\title{
Modelling the Thermomechanical and Microstructural Evolution During Rolling of a Nb HSLA Steel
}

\author{
M. PIETRZYK, C. ROUCOULES ${ }^{1)}$ and P. D. HODGSON ${ }^{2)}$
}

Akademia Górniczo-Hutnicza, University of Mining and Metallurgy, Faculty of Metallurgy and Materials Engineering, Al. Mickewicza 30, 30-059 Kraków, Poland. 1) Department of Materials Engineering, Monash University, Clayton, Victoria, Australia, $3168 . \quad 2$ 2) BHP Research-Melbourne Laboratories, 245 Wellington Rd, Mulgrave, Victoria, Australia, 3170.

(Received on November 14, 1994; accepted in final form on February 17, 1995)

\begin{abstract}
A simple approach to calculate rolling loads based on Sims' model was compared to a finite element model (FEM) using the same constitutive law and recrystallization equations. The comparison was done with a $\mathrm{Nb}$ microalloyed steel using a laboratory rolling simulation of plate and strip mill rolling schedules. The FEM model accurately predicted the temperature, the change in rolling loads, and the evolution of microstructure before and after transformation. These results clarified the accuracy of various microstructure models, particularly the model for recrystallization. The FEM model gave an improved prediction of the rolling loads slightly compared with the slab method. For on-line modelling of the rolling loads a simpler approach based on Sims model gave acceptable prediction when using an accurate temperature model to predict the average temperature throughout the rolling process. The combination of the constitutive law and recrystallization kinetics in both cases enabled the prediction of the increase in rolling loads over the entire temperature range. The results also suggest that solute drag, rather than strain induced precipitation, has the primary effect on retarding recrystallization under the conditions examined.
\end{abstract}

KEY WORDS: finite element method; Nb steel; hot rolling; recrystallization; precipitation; modelling.

\section{Introduction}

The mathematical modelling in most aspects of hot rolling has advanced significantly over the past two decades. This has enabled a more complete understanding of the various processes that occur during rolling and cooling to room temperature, as well as providing tools that can be used for analysis and control. As noted recently $^{1)}$ though, there often exists significant divergences between two approaches: one is the complex models which can only be used as off-line tools by experienced modellers and another the simple models which may still be physically based, but are constructed such that modelling skills are not essential.

The current work aims to consider one case where both simple and complex models are used for the hot rolling of steel. Here there is a need for a number of submodels to describe the thermal, mechanical and microstructural aspects that occur and which have an effect on the others. The evolution of temperature during rolling is now well understood and the various aspects which are modelled have not changed greatly since the early work of Hollander. ${ }^{2)}$ Temperature has a large effect on the mechanical behaviors through its influence on the strength of steel during rolling, and thereby the rolling load, torque and power. Temperature then affects the microstructural evolution since all processes concerned with this are thermally activated. The micro- structural evolution, in turn, has a pronounced effect on the mechanical properties, due to the higher rolling loads which can be encountered in the rolling at lower temperatures through the suppression of recrystallization between passes.

Other interrelationships between temperature, deformation and microstructure development also exist suggesting that an overall model requires a high level of sophistication and coupling. However, many workers have also shown that quite simple models are adequate and can give agreement with measurements which are within the accuracy limits of the measurement. ${ }^{1)}$ In this case, it is possible that significant tuning of the models has been used.

In the current work, both complex and simple models have been used to describe the above aspects in relation to the hot rolling of a $\mathrm{Nb}$ microalloyed steel. In the first case, the finite element model (FEM) provides a complete description of the evolution of temperature, strain rate and strain through the stock thickness and along the arc of contact. This then allows not only the bulk microstructural evolution to be followed when coupled with appropriate models, but also any inhomogeneities introduced through the above. The disadvantage of such a detailed model is the computational requirements, which currently limits this approach to offline simulations. A simple model, based on the use of average the temperature, strain and strain rate in the roll gap was 
compared with the FEM approach to assess its accuracy. This model would be suitable for online control, as it consists of a simple set of equations which can be incorporate within most modern mill control systems.

In the current work the models have also been compared with laboratory rolling data which has advantage of reproducing the actual deformation conditions while allowing accurate measurement of temperature, load and microstructure; in the latter case during both rolling and cooling to room temperature.

\section{Model Outline}

\subsection{Full Model}

The full model involved a combination of a finite element model to calculate the thermal and mechanical behaviors in rolling and a microstructure model which predicts evolution of the austenite microstructure, its transformation to the room temperature microstructure and resultant strength.

The simulation of metal flow and heat transfer, as well as predictions of loads are based on a thermalmechanical finite-element model described in detail in Ref. 2). The model couples a rigid-plastic flow formulation $^{3)}$ with the finite-element solution of the general Fourier equation describing heat transfer in the deformation zone and during the intervals between the passes. Various aspects covered by this model are briefly described below.

\subsubsection{Rolling}

The temperature distribution in the roll gap is calculated by using the finite-element solution of the general convective-diffusion equation:

$$
\nabla^{\mathrm{T}} k \nabla T+Q-c_{p} \rho v^{\mathrm{T}} \nabla T=0
$$

where ${ }^{\mathbf{T}}$ is the transpose sign.

The mechanical component of the model computes the distributions of velocities, strain rates, strains and stresses in the roll gap. The approach introduces the extremum principle which states that for a plastically deforming body in the roll gap of volume $V$ under the tractions $\boldsymbol{F}$ prescribed on a part of the boundary $S$ and the velocity $v$ prescribed on the rest of the boundary, with an incompressibility constraint imposed using the Lagrange multiplier $\lambda$, the actual velocity field minimizes the functional in local:

$$
J=\int_{V}\left(\sigma_{i} \dot{\varepsilon}_{i}+\lambda \dot{\varepsilon}_{V}\right) d V+\int_{S} \boldsymbol{F} \boldsymbol{v} d S
$$

In the rolling process, $S$ refers to the contact surface and the friction forces are the only tractions in $\boldsymbol{F}$. It is assumed in the solution that the body obeys the HuberMises yield criterion and its associated flow rule. An advantage of this approach is that the effective stress is equal to the yield strength which is determined experimentally as a function of current temperature, strain rate and strain. The boundary conditions are of $2^{\text {nd }}$ and $3^{\text {rd }}$ kind and were described in Ref. 2). Thermal and mechanical equations are solved separately and the results are iterated between the two solutions. Thus, the temperature field is calculated for each iteration during optimization of functional (2). Current velocity, strain rate and strain fields are used in temperature calculations. The temperature field is used to calculate material's local flow stress in each element.

The predictions of loads during rolling depend on the choice of the stress-strain relationship used in the calculations. The constitutive equation for the current model is based on the work by Hodgson and Collinson ${ }^{4)}$.

$$
\sigma_{p}=K \varepsilon^{m} \sinh ^{-1}(A Z)^{p}
$$

where the coefficients $K=100, p=0.2, A=2 \times 10^{-13} \mathrm{~s}^{-1}$ and $m=0.2$ are used in the finite-element model. This function was obtained directly from the torsion test. In the original work the constants given above were for the mean yield strength, rather than for the stress at a given strain, strain rate and temperature. However, it has been noted by the authors that there is no significant difference between the plane strain mean yield strength at a given strain and the equivalent tensile stress for the particular steel studied and the range of deformation conditions.

\subsubsection{Interpass Times}

The temperature variations during the interpass times are given by the finite-element transient solution of the general diffusion equation:

$$
\nabla^{\mathrm{T}} k \nabla T+Q-c_{p} \rho \frac{d T}{d t}=0
$$

As the steel comes out of the roll gap, recrystallization and precipitation are controlling evolution of the microstructure. The amount of recrystallization was calculated using an Avrami equation:

$$
X=1-\exp \left[-0.693\left(\frac{t}{t_{0.5}}\right)^{2}\right]
$$

Two models, suggested by Hodgson ${ }^{5)}$ and by Dutta and Sellars ${ }^{6)}$ (Table 1), were used in the finite element program for the analysis of the recrystallization and precipitation kinetics. In Table $1, k_{s}$ is the supersaturation ratio given by:

Table 1. Recrystallization and precipitation times in two considered models.

\begin{tabular}{c|c|c}
\hline & Hodgson $^{5)}$ & Dutta and Sellars ${ }^{6)}$ \\
\hline Recrystallization & $t_{0.5 x}=(-5.24+550[\mathrm{Nb}]) \cdot 10^{-18} D^{2} \varepsilon^{-4+77(\mathrm{Nb}]} \exp \frac{330000}{R T}$ & $t_{0.05 x}=6.75 \cdot 10^{-20} D^{2} \varepsilon^{-4} \exp \frac{300000}{R T} \exp \left[\left(\frac{2.75 \cdot 10^{5}}{T}-185\right)[\mathrm{Nb}]\right]$ \\
Precipitation & $t_{0.05 p}=6 \cdot 10^{-6}[\mathrm{Nb}]^{-1} \varepsilon^{-1} Z^{-0.5} \exp \frac{270000}{R T} \exp \frac{2.5 \cdot 10^{10}}{T^{3}\left(\ln k_{s}\right)^{2}}$ & $t_{0.05 p}=3 \cdot 10^{-6}[\mathrm{Nb}]^{-1} \varepsilon^{-1} Z^{-0.5} \exp \frac{27.0000}{R T} \exp \frac{2.5 \cdot 10^{10}}{T^{3}\left(\ln k_{s}\right)^{2}}$ \\
\hline
\end{tabular}




$$
k_{s}=\frac{[\mathrm{Nb}]\left([\mathrm{C}]+\frac{12}{14}[\mathrm{~N}]\right)}{10^{2.26-6770 / T}}
$$

It is assumed that for $t_{0.05 x}<t_{0.05 p}<t_{0.95 x}$ recrystallization is retarded by precipitation and for $t_{0.05 x}>t_{0.05 p}$ recrystallization does not take place. When there is incomplete recrystallization during the interpass period the retained strain at the entry to the next pass is calculated as:

$$
\varepsilon_{r}=\varepsilon(1-X)
$$

When full recrystallization occurs, the recrystallized grain size is calculated. Grain growth after complete recrystallization is also modelled (Table 2).

Since the steel used in the experiment contained some niobium, the grain growth equation coefficients for a $\mathrm{C}-\mathrm{Mn}-\mathrm{Nb}$ steel were used. These coefficients are ${ }^{7)}: m=$ $4.5, k_{g}=4.4 \times 10^{23}, Q_{g}=435 \mathrm{~kJ} / \mathrm{mol}$. The steel also contained $\mathrm{Ti}$ which normally suppresses growth and it was expected that may be some alteration to the grain growth equation required. However, the multiple reheats used during the initial rolling of the slab to plate and then the rolling described in this work appear to have reduced the pinning efficiency of the $\operatorname{Ti}(\mathrm{C}, \mathrm{N})$ 's, and the predictions based on the $\mathrm{C}-\mathrm{Mn}-\mathrm{Nb}$ model appear to be adequate.

The simulation of the austenite to ferrite transformation is included in the model. The empirical equation developed in Ref. 8) describing the dependence of the ferrite grain size on the austenite grain size, cooling rate and retained strain is used here (Table 2).

The microstructural equations (Tables 1 and 2) were implemented into the thermal-mechanical finite element program, and calculations of the recrystallization kinetics and the grain sizes were performed at different locations through the strip thickness. Local values of the temperatures, strain rates and strains obtained from the finite-element model were used in the microstructural equations. The additivity rule was introduced to account for the effect of temperature variations on the recrystallization and precipitation processed during the time intervals. Both precipitation and recrystallization processes were simulated according to the following principle $^{9)}$ :

Table 2. Equations describing grain size in the model.

$\begin{array}{lc}\begin{array}{l}\text { Recrystallized } \\ \text { grain size }\end{array} & D_{r}=A D^{0.67} \varepsilon^{-0.67} \\ \text { Grain growth } & D^{m}=D_{r}^{m}+k_{s} \exp \left(\frac{-Q_{g}}{R T}\right) \\ \text { Ferrite } \quad D_{\alpha}=\left(1-0.8 \varepsilon_{r}^{0.15}\right)\left\{29-5 c_{r}^{0.5}+20[1-\exp (-0.15 D]\}\right.\end{array}$

$$
X=\sum_{i=1}^{n} \frac{\Delta t_{i}}{t_{i}}
$$

where $n$ is a number of the time increments. In Eq. (7) $t_{i}$ represents the time calculated from the relevant equation for the current temperature in the time increment $\Delta t_{i}$.

\subsection{Simple Model}

The focus for the simple model was the prediction of rolling load, incorporating a simple recrystallization model. No attempt was made to calculate the austenite and ferrite grain sizes and resulting room temperature strength, as no simplifications of the model described above are currently available.

The force model used Sims formulation:

$$
P=\sigma_{p} S Q_{p}
$$

where $\sigma_{p}$ is the mean yield strength. The predicted rolling loads were calculated from Eqs. (3) and (8) compared to the measured rolling loads. The retained strain was incorporated into Eq. (3) using Eqs. (5) and (6) as described in Ref. 4) with the equation for $t_{0.5 x}$ given in Table 1.

\section{Experimental Technique}

A Nb HSLA steel, with the composition given in Table 3, was used in this study. The samples were reheated for $30 \mathrm{~min}$ at $1250^{\circ} \mathrm{C}$ in a small furnace. The samples were inserted into stainless steel bags to reduce scale formation in the furnace. The samples were then rolled in the BHPR-ML rolling mill at a rolling speed of $0.36 \mathrm{~m} / \mathrm{s}$ according to four rolling schedules. The temperature was measured using two $\mathrm{N}$ type thermocouples inserted in the mid thickness and mid length of the samples. Rolling loads were also recorded during the tests.

Tests T1, T2 and T3 were based on an approximation of a plate schedule, involving continuous cooling with a constant interpass time of $10 \mathrm{~s}$ and a constant strain for each pass. Such an approach has been termed a $T_{n r}$ test and has previously been used under controlled laboratory simulations using the hot torsion test. ${ }^{10)}$ Tests T4 and T5 were based on an approximation of a hot strip mill, with separate roughing and finishing phases. The strains and interpass times were not those encountered in actual strip rolling, but were designed to test conditions of a large number of passes with strain accumulation.

The details of each test are:

(a) $\mathrm{T} 1$ consisted of 10 passes, each of 0.15 true strain, separated by a $10 \mathrm{~s}$ interpass time.

(b) T2 consisted of 8 passes, each of 0.25 true strain, separated by a $10 \mathrm{~s}$ interpass time.

(c) T3 consisted of 6 passes, each of 0.35 true strain, separated by a $10 \mathrm{~s}$ interpass time.

(d) T4 consisted of 3 roughing passes, each of 0.25 true strain and given at fixed temperatures; then 5 finish-

Table 3. Composition of the Nb HSLA steel used. (wt\%)

\begin{tabular}{ccccccccccc}
\hline $\mathrm{C}$ & $\mathrm{P}$ & $\mathrm{Mn}$ & $\mathrm{Si}$ & $\mathrm{S}$ & $\mathrm{Ni}$ & $\mathrm{Cr}$ & $\mathrm{Al}$ & $\mathrm{Nb}$ & $\mathrm{Ti}$ & $\mathrm{N}$ \\
\hline 0.15 & 0.012 & 1.18 & 0.25 & 0.011 & 0.022 & 0.014 & 0.036 & 0.02 & 0.013 & 0.0028 \\
\hline
\end{tabular}


Table 4. Start and end temperatures for tests $\mathrm{T} 1, \mathrm{~T} 2$, and T3.

\begin{tabular}{cccc}
\hline & & $\begin{array}{c}\text { Start temperature } \\
\left({ }^{\circ} \mathrm{C}\right)\end{array}$ & $\begin{array}{c}\text { End temperature } \\
\left({ }^{\circ} \mathrm{C}\right)\end{array}$ \\
\hline \multirow{2}{*}{$\mathrm{T} 1$} & T1-1 & 1187 & 825 \\
& T1-2 & 1168 & 819 \\
& T1-3 & 1208 & 847 \\
T2 & T2-1 & 1015 & 823 \\
& T2-2 & 1200 & 838 \\
& T2-3 & 1186 & 804 \\
& T2-4 & 1162 & 794 \\
& T2-5 & 1209 & 836 \\
& T2-6 & 1192 & 1054 \\
T3 & T3-1 & 1190 & 843 \\
& T3-2 & 1042 & 796 \\
\hline
\end{tabular}

Table 5. Temperature of roughing and finishing for $\mathrm{T} 4$ and T5.

\begin{tabular}{lcccc}
\hline & \multicolumn{2}{c}{ T4 } & & T5 \\
\cline { 2 - 3 } & T4-1 & T4-2 and T4-3 & & T5-1 \\
\hline Roughing $\left({ }^{\circ} \mathrm{C}\right)$ & \multicolumn{3}{c}{1170,1110,} \\
& \multicolumn{3}{c}{1040} & \\
Entry finishing temperature $\left({ }^{\circ} \mathrm{C}\right)$ & 940 & 920 & & 920 \\
End finishing temperature $\left({ }^{\circ} \mathrm{C}\right)$ & 803 & 773 & & 800 \\
\hline
\end{tabular}

ing passes, each of 0.25 true strain and separated by a $6 \mathrm{~s}$ interpass time, were started at two entry finishing temperatures.

(e) T5 consisted of the same schedule as T4; however the true strain for each pass given during the finishing was decreased to 0.15 .

The temperatures at which the tests were started are given in Tables $\mathbf{4}$ and $\mathbf{5}$. Samples were either quenched after a certain number of passes, or air cooled to determine the prior austenite and ferrite structure, respectively. A longitudinal section corresponding to the position of the thermocouples was investigated using optical microscopy. The prior austenite and ferrite grains were etched using a picral and a nital etchant, respectively. The average grain size was estimated by the line intercept method at the centre of the strip and at the surface.

\section{Experimental Results and Comparison with Models}

\subsection{Temperature}

The accuracy of the FEM solution for heat transfer depends on the evaluation of the boundary conditions: in particular the heat transfer coefficient to the roll and to the surrounding air. The heat transfer coefficient for the roll-workpiece interface was chosen as $20 \mathrm{~kW} / \mathrm{m}^{2} \mathrm{~K}$ on the basis of the analysis presented in Ref. 11). Since the samples were protected from scaling during heating, the maximum value of the heat transfer coefficient reported in Ref. 11) has been chosen. The air cooling was simulated using typical convection and radiation equations. A multiplier of 1.1 was applied to account for the contact of the sample with the roller table.

The calculated history of temperature agreed closely
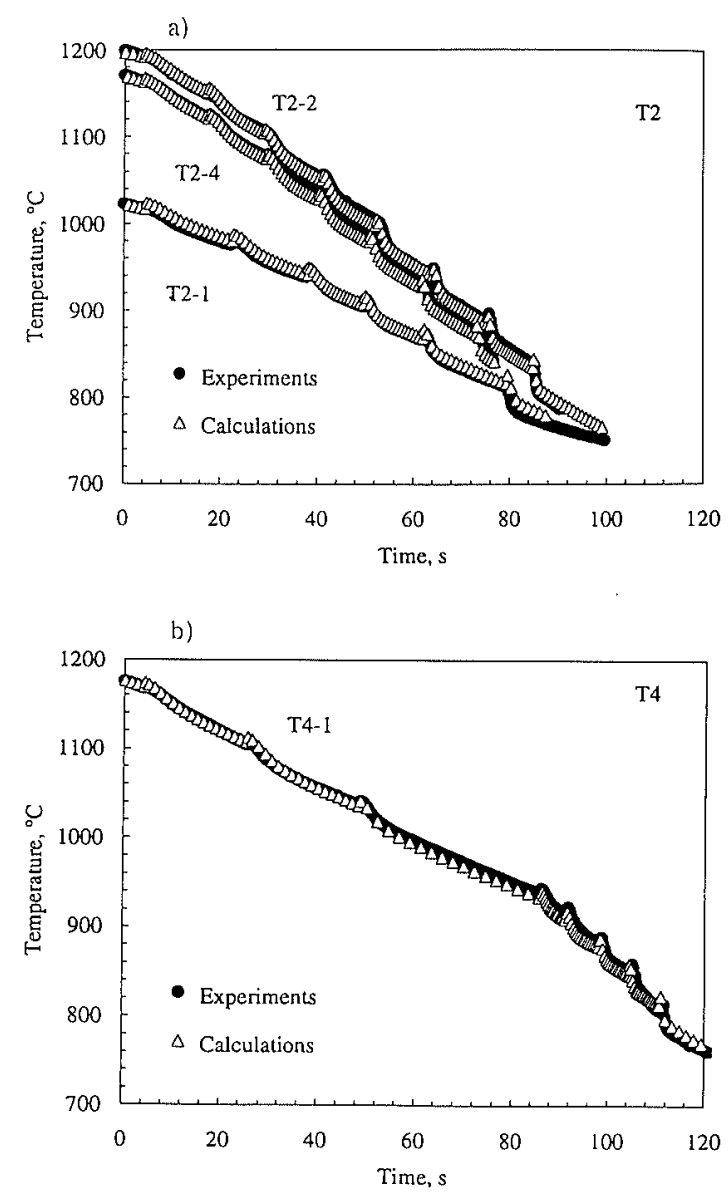

Fig. 1. Comparison of the temperature predictions and measurements for a) T2 and b) T4.

with the measured data (Fig. 1), confirming the validity of the present model. Due to air cooling of the surface and the chilling effect of the contact between the pate and the rolls, the temperature at the surface was 80 to $140^{\circ} \mathrm{C}$ less than the centre temperature, while the average temperature of the strip (which is averaged from the surface to the centre to represent the gradient through the plate) was slightly less than the calculated temperature at the centre.

\subsection{Loading Conditions}

\subsubsection{FEM Model}

During this phase of the analysis, the FEM model was also compared with a slab model described in Ref. 2). The constitutive equation used in the two methods was Eq. (3). In both calculations, it was assumed that full recrystallization was taking place after each pass. An example of the comparison between these two methods and the measured rolling loads is given in Fig. 2 for the simulated plate schedule T2. The FEM calculation gave slightly higher values than the slab method. Both models gave a good prediction of the rolling loads from the first pass to the $6^{\text {th }}$ pass for $T 2-5$. The spread of rolling data for a given pass is quite large for the $4^{\text {th }}$ and subsequent passes and this is due to the impact between the rolled piece and the rolls, which becomes more pronounced as the steel becomes harder. The comparison between measurement and prediction was, therefore, based on the loads measured after the transient caused by the impact. 


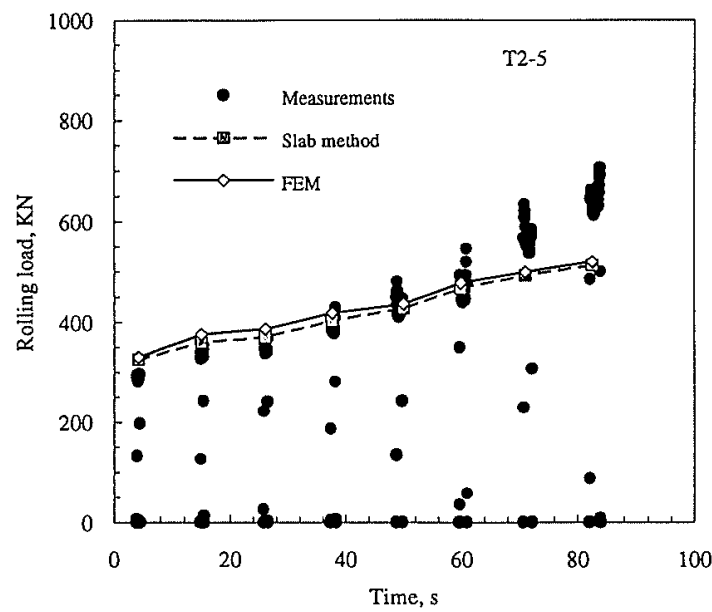

Fig. 2. Comparison of loads measured and calculated by FEM and the slab method for $\mathrm{T} 2$ when assuming full recrystallization.
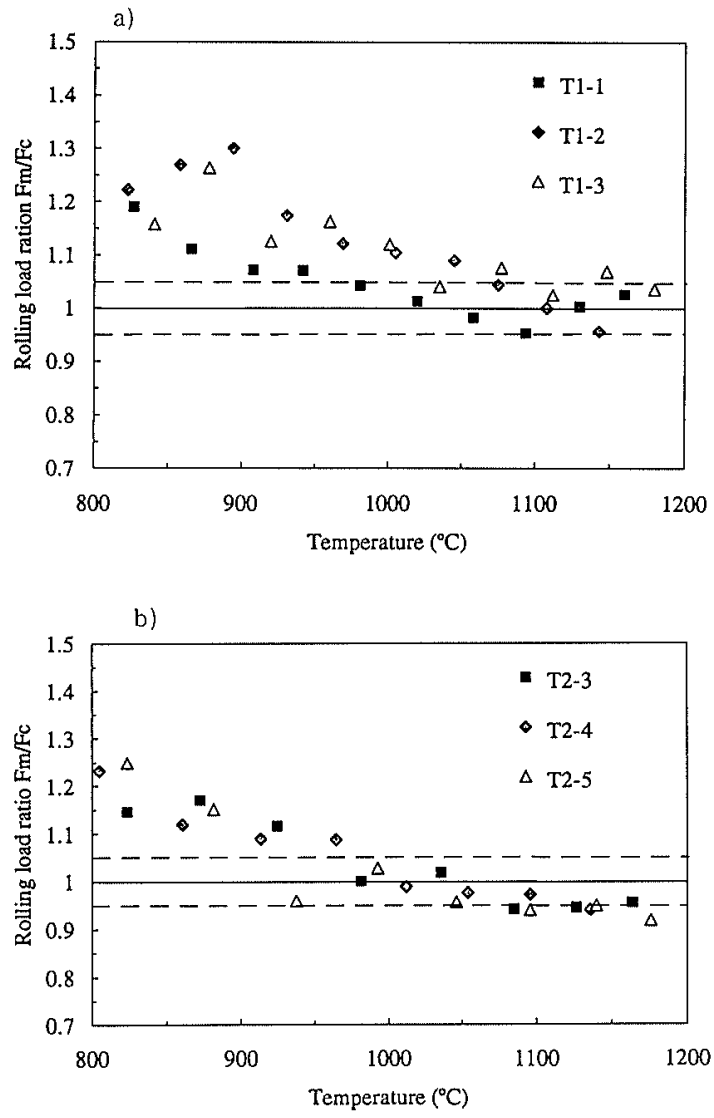

Fig. 3. Evolution of the measured to predicted rolling force ratio from FEM with rolling temperature for a) T1 and b) $\mathrm{T} 2$.

The experimental rolling loads then increased at a much higher rate than the model predictions, presumably due to the retained strain accumulation from one pass to another.

A more convenient way of representing this data is to consider the ratio of measured loads to those calculated by FEM assuming complete recrystallization for each schedule as a function of temperature (Fig. 3). The temperature here is the average temperature predicted from the temperature model. At high temperatures, the ratio remained within $5 \%$ of the measurements for each

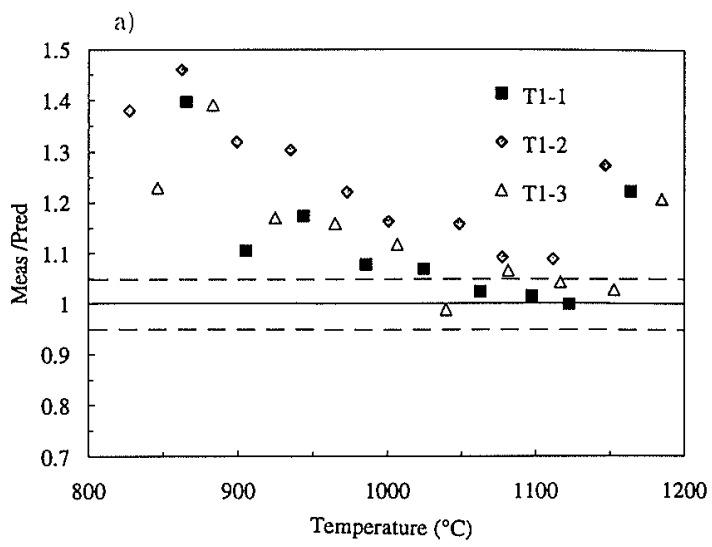

b)

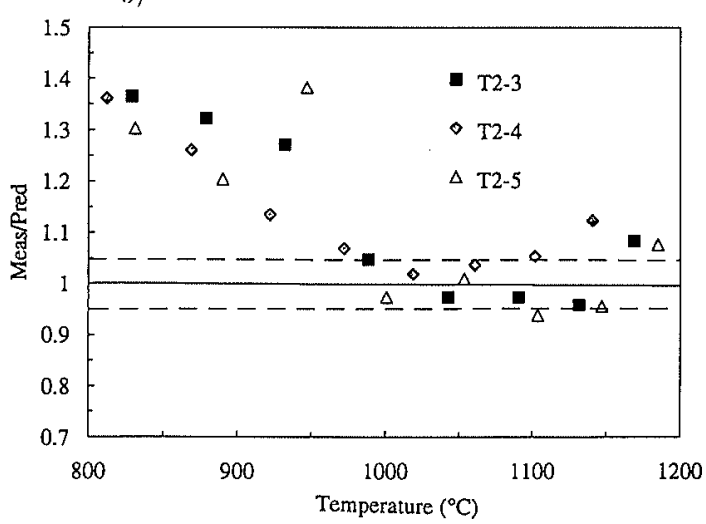

Fig. 4. Evolution of the measured to calculated load ratio from Sims with rolling temperature for a) $\mathrm{T} 1$ and b) T2.

schedule. For lower temperatures, a deviation from the prediction is observed. The experimental rolling loads were up to $30 \%$ higher than the predictions. Deviations were observed at temperature below about 1040 and $960^{\circ} \mathrm{C}$ for schedules $\mathrm{T} 1$ and $\mathrm{T} 2$, respectively.

\subsubsection{Sims Model}

The average temperature used in the FEM model was also used to calculate the predicted rolling loads using the sinh law (Eq. (3)) and the Sims model (Eq. (8)). In general, the predicted rolling loads were lower than those measured (Fig. 4). For reductions per pass larger than $25 \%(\mathrm{~T} 2, \mathrm{~T} 3, \mathrm{~T} 4)$ above $1000^{\circ} \mathrm{C}$, the predicted rolling loads were in closer agreement with the experiments than for T1, which involved a lower reduction per pass. However, the agreement for the first was poor in all cases. As the temperature decreased, the experimental rolling loads deviated to higher values than the model. The transition took place at about 1040 and $960^{\circ} \mathrm{C}$ for $\mathrm{T} 1$ and $\mathrm{T} 2$, respectively, in close agreement with the FEM predictions.

\subsection{Evolution of Microstructure}

\subsubsection{Austenite}

Samples quenched after pass numbers $3\left(1040^{\circ} \mathrm{C}\right)$ and $5\left(940^{\circ} \mathrm{C}\right)$ for schedule $\mathrm{T} 2$ showed fully and partially recrystallized microstructures in the centre of the strip, respectively. However, when quenched after pass 6 at $870^{\circ} \mathrm{C}$, the microstructure was pancaked (i.e. non recrystallized). This change in microstructure corresponds to the deviation of the experimental rolling loads from 
that predicted assuming complete recrystallization between passes.

The average austenite grain sizes for $\mathrm{T} 2$ calculated using the FEM model were in good agreement with the measurements (Fig. 5). The starting austenite grain size was measured to be $100 \mu \mathrm{m}$. As the number of deformations increase and the temperature decreases, the austenite grain size was refined to $20 \mu \mathrm{m}$. These measurements reflect the combination of both recrystallization and grain growth. The FEM model predicted that grain growth was significant during the interpass time at high temperatures. Without the incorporation of this component the prediction of microstructure and change in recrystallization behaviour was inaccurate.

\subsubsection{Ferrite}

Examples of the ferrite microstructures obtained in the centre of the strip after starting at $1165^{\circ} \mathrm{C}$ for schedules $\mathrm{T} 1$ and $\mathrm{T} 2$ are shown in Fig. 6. The microstructures were more inhomogeneous for $\mathrm{T} 1$ and $\mathrm{T} 5$, which had low strain per pass, than for T2, T3 and T4. A finer microstructure with a smaller volume fraction of pearlite was observed at the surface.

The ferrite grain size for tests T1, T2, T4 and T5 with different start temperatures was adequately predicted, as shown in Table 6. Interestingly, a lower start temperature, which resulted in a lower finishing temperature, resulted in a larger grain size for $\mathrm{T} 2$ in the centre. This reflects the lower number of passes in the non-recrystallized region.

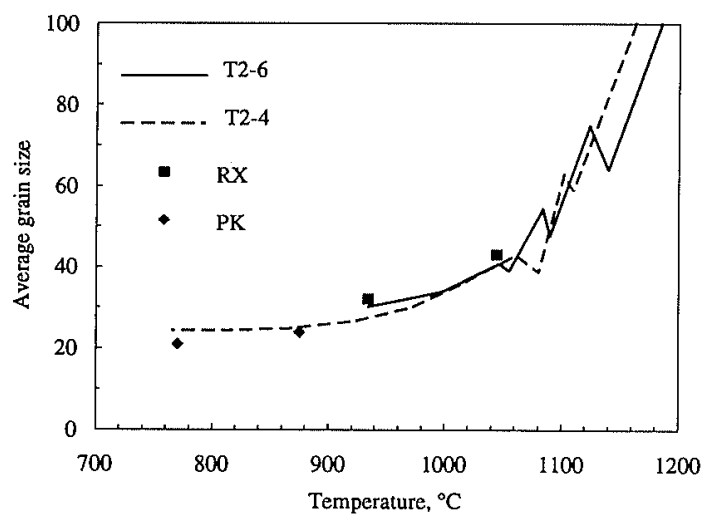

Fig. 5. Evolution of the predicted and measured austenite grain size during $\mathrm{T} 2$.

\section{Discussion}

\subsection{Strain Distribution Predicted by FEM}

In general, homogeneous deformation is assumed during rolling when calculating rolling loads. However, in reality the situation is more complex, as friction affects the strain distribution. FEM provides a more accurate determination of the strain and strain rate distribution in the roll gap and its influences on the microstructure and rolling force. In the FEM model, velocity dependent slipping friction was assumed. An example of strain distribution for pass 6 in T4-1 is given in Fig. 7. The result of friction is that the effective strain is higher at the

a)

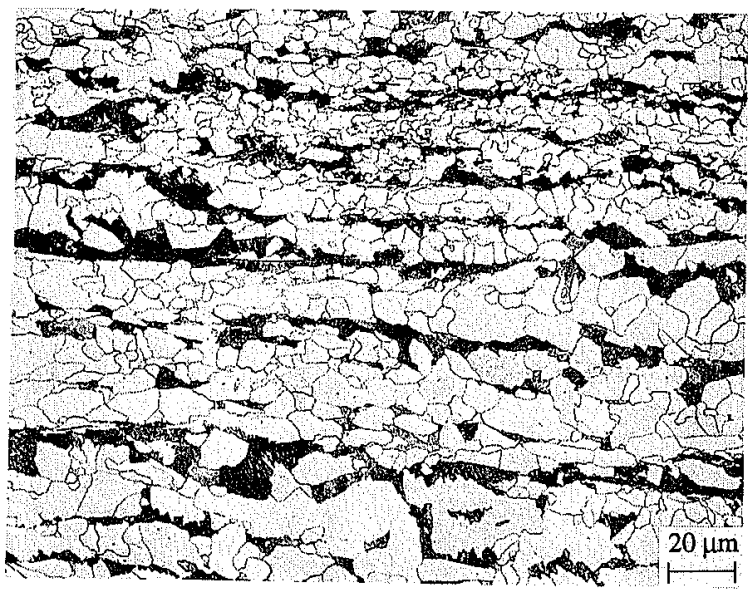

b)

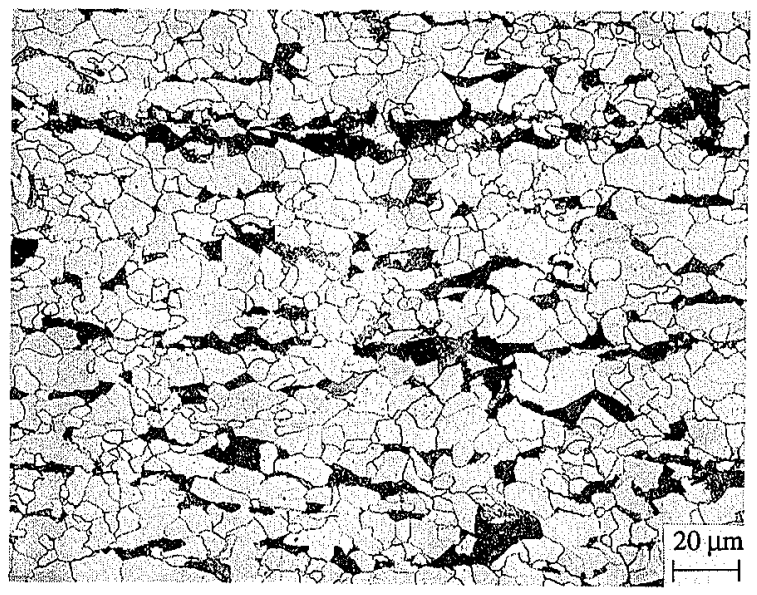

Fig. 6. Example of ferrite microstructures for a) $\mathrm{T} 1$ and b) $\mathrm{T} 2$ in the centre of the strip.

Table 6. Comparison of the calculated and measured ferrite grain size.

\begin{tabular}{|c|c|c|c|c|c|}
\hline \multirow{3}{*}{ Tests } & \multirow{3}{*}{ Temperature } & \multicolumn{4}{|c|}{ Ferrite grain size $(\mu \mathrm{m})$} \\
\hline & & \multicolumn{2}{|c|}{ Centre } & \multicolumn{2}{|c|}{ Surface } \\
\hline & & Measured & Calculated & Measured & Calculated \\
\hline \multirow[t]{2}{*}{$\mathrm{T} 2$} & $\mathrm{~T} 2-4,1162^{\circ} \mathrm{C}$ & 8.4 & 7.4 & 7.0 & 6.5 \\
\hline & $\mathrm{T} 2-5,1220^{\circ} \mathrm{C}$ & 6.4 & 6.4 & 7.1 & 5.6 \\
\hline \multirow[t]{2}{*}{$\mathrm{TI}$} & $\mathrm{T} 1-1,1187^{\circ} \mathrm{C}$ & 7.3 & 8 & 5.5 & 6.8 \\
\hline & $\mathrm{T} 1-2,1168^{\circ} \mathrm{C}$ & 8.4 & 8.2 & 6.4 & 6.7 \\
\hline \multirow[t]{2}{*}{$\mathrm{T} 4$} & $\mathrm{~T} 4-1,1169^{\circ} \mathrm{C}$ & 7.4 & 6.1 & 6.3 & 5.0 \\
\hline & $\mathrm{T} 4-2,1170^{\circ} \mathrm{C}$ & 4.8 & 6.1 & 3.3 & 4.6 \\
\hline T5 & T5-1 & 6.3 & 7.7 & 3.6 & 5.9 \\
\hline
\end{tabular}



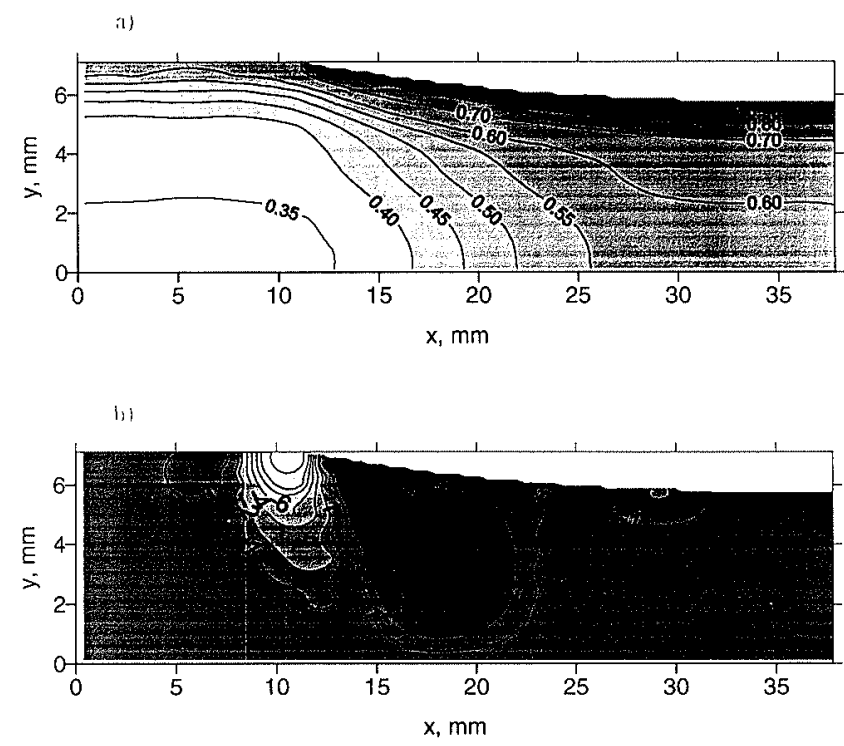

Fig. 7. Effective (a) strain and (b) shear strain rate distributions for pass 6 in T4 calculated through the strip by FEM.

surface than at the centre. When partial recrystallization occurs, the retained strain increases the strain inhomogeneity in the subsequent pass. This is shown in Fig. 7b) where the distribution of the redundant strain rates is presented. Nonuniform strains carried from the previous pass enter the roll gap and lead to an intensive shearing at some distance below the surface. As a consequence, the maximum redundant strain rates are not located near the contact surface which differs from previous results for rolling with full recrystallization. ${ }^{2)}$

\subsection{Load Prediction}

\section{a) FEM Model}

It is shown in Ref. 2) that, when proper description of the material properties is used, even the closed form equations or the slab method can predict the rolling loads with reasonably good accuracy, as shown in the current work (Fig. 2). It is often observed, however, that the stress-strain relationship fitted to a particular closedform load equation, which does not account for shear strains, gives excessive values when introduced into the finite-element model. Moreover, the conventional closedform equations calculate loads based on the entry temperature at the centre of the strip while the finite-element models predict the distribution of the temperature in the deformation zone.

\section{b) Sims}

The material constants used in the constitutive equation (Eq. (3)) gave a relatively good fit during roughing or at high temperatures, when using the average temperature (Fig. 4). The comparison of the FEM and Sims models, when assuming full recrystallization, reveals a larger variation in the ratio of measured to predicted load in the latter. The first pass in the Sims model is not as well predicted as in the FEM. At lower temperatures FEM gives a lower ratio than Sims. As shown above, strain and strain rate inhomogeneity occurs in the roll gap as partial recrystallization takes place. However

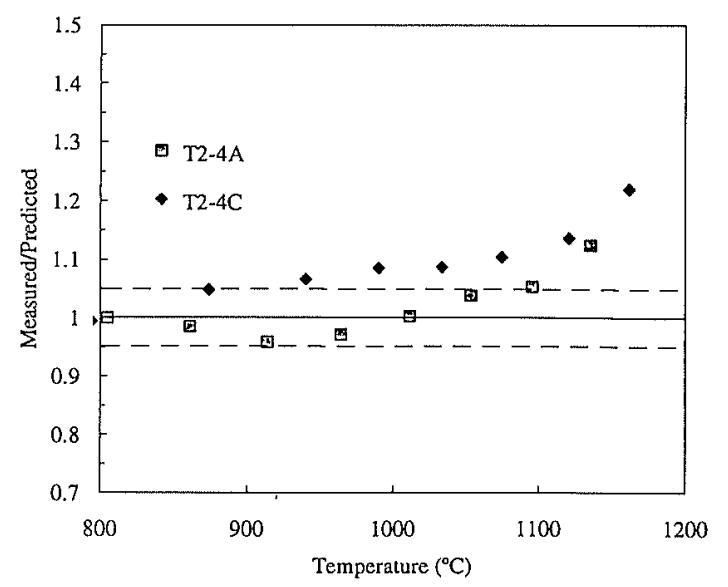

Fig. 8. Evolution of the measured to predicted load ratio for the average $(\mathrm{T} 2-4 \mathrm{~A})$ and centre $(\mathrm{T} 2-4 \mathrm{C})$ temperature from Sims as a function of the rolling temperature for $\mathrm{T} 2$.

Sims' model is based on an average strain and does not include the non uniform strains and strain rates near the surface. As a result it underestimates the rolling loads and gives a higher measured over predicted load ratio.

The accuracy of Sims' model is also strongly dependent on the knowledge of the average temperature. When the measured centre temperature was used as an approximation of the average temperature, the material constants used in the constitutive equation failed to describe the hot strength calculated by Sims (Fig. 8). This result shows that an accurate temperature model is required to predict the bulk or average temperature. One of the problems with on-line models of this type is that it is possible to obtain a good fit by adjusting the hot strength constants. However, this tends to limit the general applicability of the on-line model and reduces the ability of the adaptation scheme, used within the mill control system, to settle down over time.

\subsection{Effect of Strain Accumulation on Rolling Loads} a) FEM

Although the hot strength, and thereby load, can be predicted at high temperature by Sims (Fig. 4), or by FEM (Figs. 2 and 3) there was significant deviation as the temperature decreased. Full recrystallization was assumed to take place in the model. However, below $1000^{\circ} \mathrm{C}$, solute drag effects and precipitation of $\mathrm{NbC}$ can take place and inhibit or completely stop recrystallization. As a result, strain accumulation takes place and the hot strength increases. To predict the hot strength at lower temperature, the recrystallization kinetics and the amount of strain accumulated have to be determined. It is also important to predict the point at which recrystallization finishes especially at high temperature, as grain growth takes place rapidly in the remaining time before the next deformation (Fig. 5). Accurate prediction of the grain size earlier during the roughing stage is necessary, as it influences the recrystallization kinetics after the next pass.

Two recrystallization models were tested: Sellars ${ }^{6)}$ and Hodgson. ${ }^{5,7)}$ For both models the rolling loads predicted by FEM were better modelled for the simulated plate 
schedule (T1 and T3 shown in Fig. 9) and for the simulated hot strip schedule (T5 in Fig. 10) when adding the recrystallization model and taking into account the retained strain. However, the introduction of the Sellars recrystallization model predicted lower loads as the temperature decreased especially for large reductions. This model tended to predict faster recrystallization kinetics than the Hodgson model (Fig. 10). As a result, the Sellars model predicted retained strain later than observed in the experiments, and failed to predict the occurrence of partial recrystallization that was observed metallographically in T2 after the fifth pass.

The accuracy of the recrystallization model was found

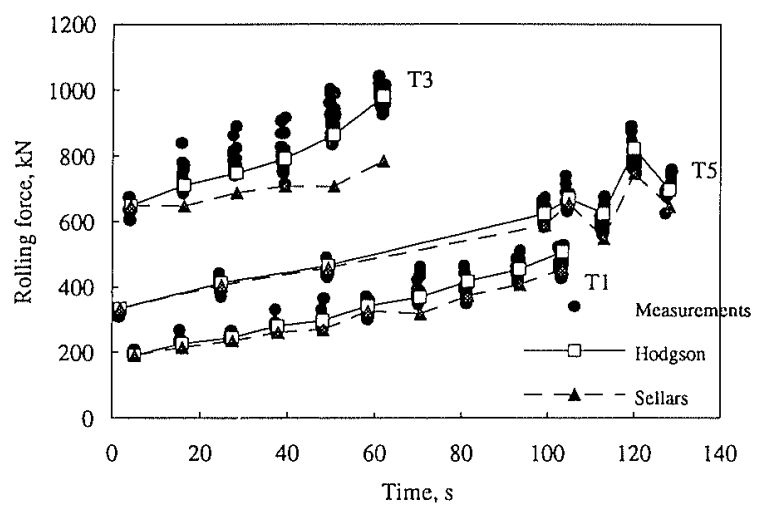

Fig. 9. Comparison of the measured rolling loads with the predicted rolling loads by FEM for $\mathrm{T} 1, \mathrm{~T} 2$ and $\mathrm{T} 3$ when using the recrystallization models of Sellars ${ }^{6)}$ and Hodgson. ${ }^{5 \text { ? }}$

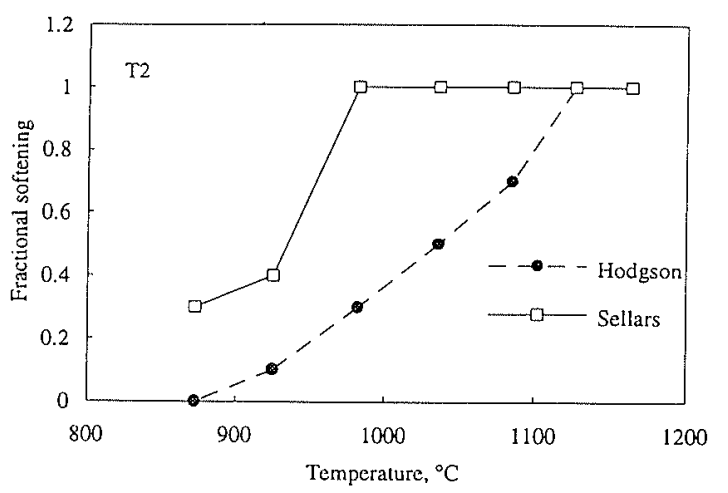

Fig. 10. Comparison of the predicted fractional softening by Hodgson and Sellars for T2.

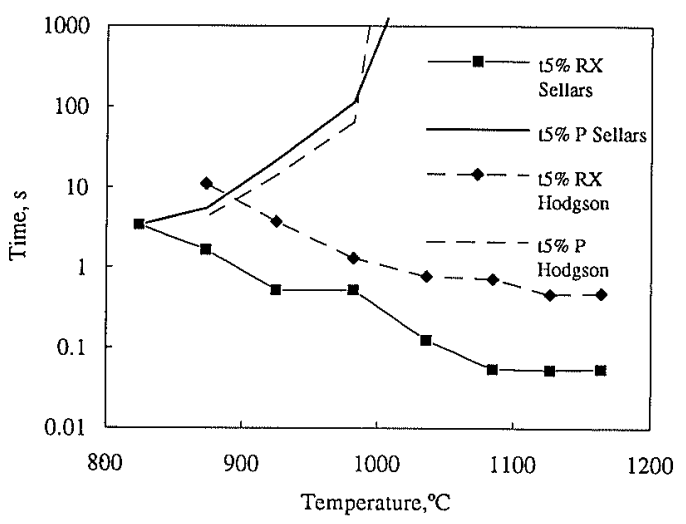

Fig. 11. Evolution of the recrystallization times $t_{5 \%}$ and of the precipitation start time after each pass for T2 using the Sellars model, and the Hodgson model. to have a greater effect on the prediction of the rolling loads than the actual expression of the strain accumulation. The coefficient in the strain accumulation Eq. (6) is reported to be between 0.5 and $1 .{ }^{7)}$ Simulations with each factor gave only minor difference, except for the lower applied strain. Overall, though, using a coefficient of 1 in Eq. (6) and the Hodgson recrystallization model, gave the most accurate prediction over the entire range of conditions studied.

The time for $5 \%$ strain induced precipitation was estimated and compared to the time for 5\% recrystallization. An example is shown for T2 in Fig. 11. Precipitation was predicted to stop recrystallization at $890^{\circ} \mathrm{C}$ using the Hodgson model and at $820^{\circ} \mathrm{C}$ by the Sellars model. Therefore precipitation does not account for the
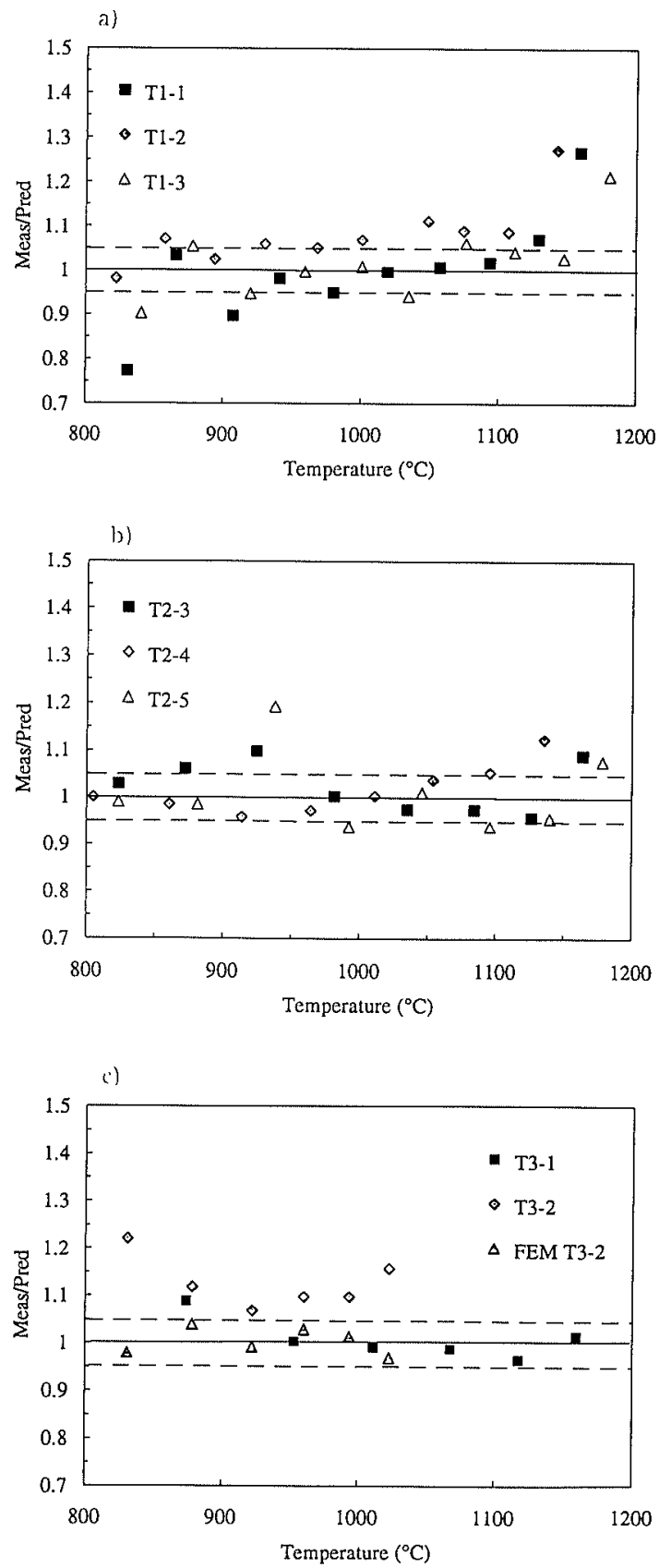

Fig. 12. Evolution of the measured to predicted load ratio from Sims calculated from Eq. (4) and the Hodgson recrystallization model as a function of the rolling of temperature for a) $\mathrm{T} 1, \mathrm{~b}) \mathrm{T} 2$ and c) $\mathrm{T} 3$. 
deviation in load and strength at 1040 and $960^{\circ} \mathrm{C}$ observed in Fig. 3 when assuming full recrystallization. Solute drag is therefore responsible for the retardation of recrystallization in this range of temperatures.

b) Sims

The recrystallization model of Hodgson was incorporated into the hot strength model, using the coefficients given above and the average temperature. The retained strain was determined using Eq. (6). As the on-line model has to be as simple as possible, the recrystallization kinetics were calculated assuming a constant grain size of $40 \mu \mathrm{m}$ instead of the calculated grain size at each pass, as in the FEM model. Figure 12 shows the data from Fig. 4 and the T3 test using the combined model. The temperature at which the rate of increase of the rolling loads changes has been called the $T_{n r}$ temperature or temperature of non recrystallization. As shown above, this temperature is related to the start of partial recrystallization and the increase in retained strain. Thus the modelling of rolling loads can be simply achieved by a temperature model, a constitutive equation and an accurate knowledge of recrystallization kinetics, without the knowledge of precipitation start time. Such an approach appears to be adequate for the prediction of rolling loads, despite the non uniform strains and strain rates through the roll gap (5.2b). The importance of strain inhomogeneity and microstructural change on
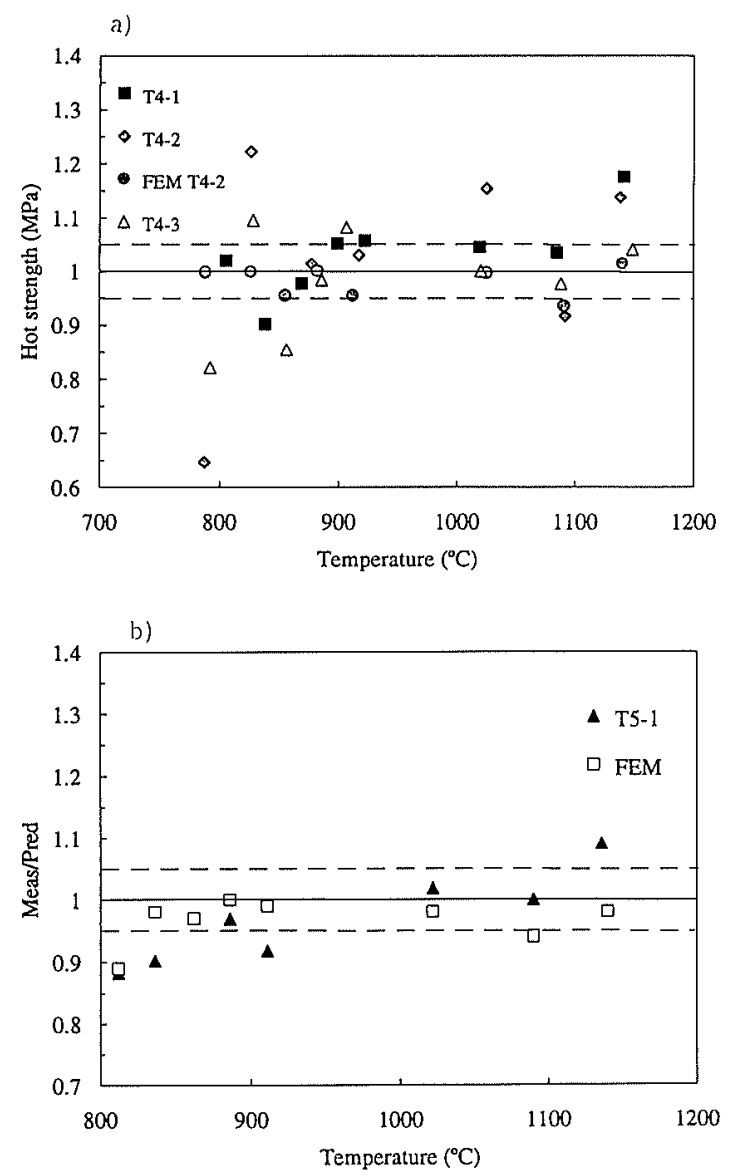

Fig. 13. Evolution of the measured to predicted load ratio from Sims calculated from Eq. (4) and the Hodgson recrystallization model with rolling temperature for a) $\mathrm{T} 4$ and b) $\mathrm{T} 5$. rolling loads is shown in Fig. 12c), where the FEM gives a measured over predicted ratio closer to 1 for T3-2 than Sims' model. One weakness of the present model is the assumption of an average grain size of $40 \mu \mathrm{m}$ for all schedules. However, better accuracy could be obtained if the grain size could predicted on-line, or a simple model regressed from the detailed model.

The model was also relatively successful in modelling the simulation of hot strip mill (Fig. 13), although for low reductions the model tended to overestimate the rolling loads during strain accumulation. This could be due to the power law dependence used in the constitutive equation (Eq. (3)). One weakness of that constitutive equation is that the parameters are only valid over a limited range of strain $(0.2-0.6)$. For smaller reductions or large retained strains the material constant of Eq. (3) may need to be adapted to compensate for the deviation in the model. A solution would be to use a constitutive equation valid over a larger range of strain.

\subsection{Microstructure}

The evolution of microstructure during rolling and on transformation during cooling was found to be accurately predicted using equations previously developed by one of the current authors and colleagues. ${ }^{7)}$ By contrast the Sellars model was unable to predict the microstructural evolution, primarily as it gave quite different predictions for the static recrystallization kinetics. The other equations developed by Sellars and co-workers for grain growth and the transformed ferrite grain size ${ }^{13,14)}$ were not studied in detail, although some results suggest that the equation for ferrite grain size did not provide an accurate prediction, even when combined with the more accurate recrystallization model.

It is beyond the scope of this limited number of rolling experiments to discuss the potential causes for deviation between the recrystallization models and the measurements, except to suggest that in the case of the data used for the Hodgson model and the data generated here, there was significant thermomechanical processing of the austenite prior to the pass where recrystallization was halted. Dutta et al. $^{12)}$ have suggested that roughing can have a major effect on the kinetics of strain induced precipitation. However, this would not be expected to be a major cause as the difference appeared in the early passes where solute drag seems to be the main cause for recrystallization retardation. However, the potential segregation of solute and other impurities in reheated and non deformed steels compared with extensively deformed steels may account for some of the differences. Also the recrystallization model developed by Hodgson was based on steels with a composition closer to that used in the current work (i.e. low $\mathrm{Nb}$ and $\mathrm{Ti}$ ), whereas the data used by Sellars was for higher $\mathrm{Nb}$ steels.

The detailed applicability of the strain induced precipitation model could also not be evaluated in this work, as recrystallization was being initially halted by solute drag. By running the model for some scenarios without the strain induced precipitation model, however, it did appear that there were some cases where recrystallization due to strain accumulation would have been ex- 
pected. Hence, at least qualitatively it appears that strain induced precipitation, which then eliminates any subsequent recrystallization, is occurring during the rolling experiments. From a modelling perspective this only requires strain induced precipitation to be predicted at any time prior to the onset of recrystallization through strain accumulation.

The prediction of ferrite grain size and its through thickness distribution appeared to be adequate. However, it must be noted that the sensitivity of this parameter to the upstream microstructure evolution is relatively weak due to the presence of retained strain. The reasons for this have been discussed elsewhere. ${ }^{8)}$ Therefore, the main requirement for the model to predict ferrite grain size in the current experiments was to correctly model the recrystallization kinetics, as discussed above. However, the level of agreement and certainly the relative trends where the model predicted one schedule being coarser than another were excellently reproduced.

The one aspect which was not covered in the current work was the prediction of final mechanical properties. For microalloyed steels this requires not only an accurate prediction of the ferrite grain size, but also the amount of precipitation strengthening. The latter, in turn, relies on accurate prediction of the amount of $\mathrm{Nb}$ precipitated prior to transformation and the hardening increment provided by the residual $\mathrm{Nb}$. In this case it is extremely important that the onset of strain induced precipitation be accurately modelled. This is an area which is now being addressed by many workers, but which is still not adequately handled.

\section{Conclusions}

The FEM model consisted of thermal, mechanical and microstructural submodels. This model, combined with accurate constitutive, recrystallization and microstructure equations based on physical metallurgy can be used off-line to optimise a rolling process or microstructure. The main features are the following:

(1) The measured temperature evolution was accurately predicted when using a heat transfer coefficient between the stock and the rolls of $20 \mathrm{~kW} / \mathrm{m}^{2} \mathrm{~K}$.

(2) The FEM model predicted the inhomogeneity of strain through the roll gap and its effect on the rolling loads. Despite its limited validity due to the use of a power law in the hot strength model, the rolling loads were accurately predicted when full recrystallization was taking place. The FEM model predicted the rolling loads slightly better than the slab method.

(3) A recrystallization model was necessary to predict the increase in rolling loads as partial recrystallization took place at lower temperature. The Hodgson recrystallization model gave an improved prediction of the change in rolling loads and the austenite grain size than the Sellars model.

(4) The final ferrite grain size through the thickness was accurately predicted using the Gibbs et al. grain size model.

For on-line modelling of the rolling loads a simpler model based on Sims force model gave acceptable pre- diction, despite the assumption of average strain through the roll gap. This approach gives a reasonable compromise between accuracy and the requirement of on-line modelling. The combination of an accurate constitutive law and a model for the recrystallization kinetics enabled the prediction of the increase in rolling loads with decreasing temperature, without the use of a model for strain induced precipitation.

The accuracy of the force model is highly dependent on the knowledge of the average temperature. Hence, an accurate temperature model is necessary to predict the average temperature throughout the rolling process.

\section{Acknowledgments}

The authors wish to thank The Broken Hill Proprietary Co., Ltd. for providing laboratory facilities and financial support for one of the authors (CR) to undertake the work reported here. They also acknowledge the technical support of colleagues at these laboratories. The work described here was funded under the ARC Grant "Deformation of Metals" and one of the authors (MP) is grateful for the financial support provided by that grant which allowed the period of sabbatical study at Monash University during which this work was performed.

\section{Nomenclature}

$S$ : contact area

$[\mathrm{C}],[\mathrm{Nb}],[\mathrm{N}]$ : carbon, niobium and nitrogen contents, respectively

$c_{p}:$ specific heat

$D:$ austenite grain size

$D_{r}$ : recrystallized grain size

$D_{\alpha}:$ ferrite grain size

$k$ : conductivity

$Q:$ heat generated due to plastic work done

$Q_{p}:$ geometric term in Sims equation

$R:$ gas constant

$T:$ temperature

$t:$ time

$t_{0.05 p}:$ time for $5 \%$ precipitation

$t_{0.05 x}:$ time for $5 \%$ recrystallization

$t_{0.5 x}$ : time for $50 \%$ recrystallization

$t_{0.95 x}:$ time for $95 \%$ recrystallization

$\boldsymbol{v}$ : vector of velocities

$X$ : recrystallized volume fraction

$Z$ : ZenerHollomon parameter

$\varepsilon:$ strain

$\dot{\varepsilon}_{i}$ : effective strain rate

$\dot{\varepsilon}_{V}: \quad$ volumetric strain rate

$\lambda:$ Lagrange multiplier

$\rho:$ density

$\sigma_{i}:$ effective stress

$\sigma_{p}:$ yield strength

\section{REFERENCES}

1) P. D. Hodgson, D. McFarlane and R. K. Gibbs: 1st Int. Conf Modelling of Metal Rolling Processes, London, September 1993 Inst. of Materials, London, (1993), 1

2) M. Pietrzyk and J. G. Lenard: Thermal-Mechanical Modelling of the Flat Rolling Process, Springer-Verlag, Berlin, (1991).

3) S. Kobayashi, S. I. Oh and T. Altan: Metal Forming and Finite 
Element Method, Oxford University Press, New York-Oxford, (1989).

4) P. D. Hodgson and D. C. Collinson: Proc. Symp. Mathematical Modelling of Hot Rolling of Steel, ed. by S. Yue, Hamilton, (1990), 239.

5) P. D. Hodgson: Mater. Forum, 17 (1993), 403.

6) B. Dutta and C. M. Sellars: Mater. Sci. Technol., 3 (1987), 197.

7) P. D. Hodgson and R. K. Gibbs: ISIJ Int., 32 (1992), 1329.

8) R. K. Gibbs, B. A. Parker and P. D. Hodgson: Proc. Symp. Low-Carbon Steels for 90's, ed. by R. Asfahani and G. Tither, TMS, Pittsburgh, (1993), 173.

9) L. N. Pussegoda, P. D. Hodgson and J. J. Jonas: Mater. Sci.
Technol., 8, (1992), 63.

10) R. Barbosa, F. Boratto, S. Yue and J. J. Jonas: Processing, Microstructure and Properties of HSLA Steels, ed. by A. J. De Ardo, TMS-AIME, Warrendale, PA, (1988), 51.

11) M. Pietrzyk, H. Kusiak, J. G. Lenard and Z. Malinowski: Proc. Conf. Formability '94, ed. by J. Bartecek, Ostrava, (1994), 329.

12) B. Dutta, E. Valdes and C. M. Sellars: Acta Metall. Mater., 40 (1992), 653.

13) C. M. Sellars: Hot Working and Forming Processes, ed. by C. M. Sellars and G. J. Davis, The Metals Soc., London, (1979), 3.

14) J. H. Beynon and C. M. Sellars: High Strength Low Alloys Steels, ed. by D. P. Dunne and T. Chandra, Wollongong, (1984), 142. 